\title{
To study umbilical cord blood TSH values in newborn in BHMRC over a period of 1 year
}

\author{
$\operatorname{Garg} \mathbf{P}^{1}$ \\ ${ }^{1}$ Dr Pratibha Garg, Assistant Professor, Department of Obstetric \& Gyenecology, Gajra Raja Medical College, M.P, India
}

Address for Correspondence: Dr Pratibha Garg, Email: drgargpratibha@gmail.com

\begin{abstract}
Objectives: To study the association between umbilical cord blood TSH values and innate factors namely sex, birth, weight, gestational age. To study the effect of birth asphyxia on cord blood TSH. To estimate incidence of congenital hypothyroidism in new borns. Methods: This study was carried out at Batra Hospital and Medical Research Centre, New Delhi from July 2008 to June 2009. Cord blood was collected immediately after birth and sent for TSH assay. Result: In our study, we found no significant difference in cord blood TSH according to mode of delivery, pre-eclampsia, birth weight, male and female newborns. We found a significantly high mean cord blood TSH in newborn with APGAR $<7$. One newborn was found to have congenital hypothyroidism. Conclusion: This study helps to find out normative and mean values of cord blood TSH and to evaluate the effect of various perinatal factors on umbilical cord blood TSH.
\end{abstract}

Key words: TSH, Cord blood, congenital hypothyroidism, Preeclampsia,

\section{Introduction}

The horror of congenital hypothyroidism and joy of its treatment can never have been expressed more vividly than by William Osler, writing in 1897 soon after the effect of thyroid replacement was recognized. 'No type of human transformation is more distressing to look at than an aggravated case of cretinism. The stunted stature, the semi-bestial aspect, the blubber lips, retrousse nose sunken at the root, the wide-open mouth, the lolling tongue, the small eyes half-closen with swollen lids, the stolid expressionless face, the squat figure, the muddy, dry skin, combine to make the picture of what has been well termed the "pairah of nature" Not the magic wand of Prospero or the brave kiss of the daughter of Hippocrates ever effected such a change as that which we are now enabled to make in these unfortunate victims, doomed heretofore to live in hopeless imbecility, an unspeakable affliction to their parents and their relative' [1]. Congenital hypothyroidism $(\mathrm{CH})$ is a major preventable cause of mental retardation. It is one of the most common endocrinopathies encountered in newborns. Although it

Manuscript received: $24^{\text {th }}$ Jan 2016

Reviewed: $04^{\text {th }}$ Feb 2016

Author Corrected; $12^{\text {th }} \mathrm{Feb} 2016$

Accepted for Publication: 22 ${ }^{\text {nd }}$ Feb 2016 affects various aspects of growth and development, its most deleterious effect is on nervous system as thyroid hormones are essential for it's development [2,3]. Thyroid hormone deficiency in fetal life, at birth or in early infancy results in retention of infantile characteristics of the brain, hypoplasia of cortical neurons with poor development of cellular processes, retarded myelination and reduced vascularity [4].

Not until 60 years later was it first reported that although thyroid replacement treatment did indeed abolish the physical manifestations of congenital hypothyroidism, unless it was started within the first few weeks of life, serious intellectual and neurological deficits frequently persisted [5].

This remained a matter of controversy but was supported by increasing weight of evidence. In 1972 a study from Pittsburgh, for instance, showed that treatment started before the age of 3 months resulted in a mean intelligence quotient (IQ) of 89 , between 3 and 6 months of 70, and after 6 months of only 54 [6].

The potential benefit of neonatal screening was evident, and when radioimmunoassays became available for 
measurement of thyroxine and later thyroid stimulating hormone in small samples of serum or whole blood spotted on the filter paper, pilot programs were organized without delay.

In 1973 screening was started in Pittsburgh using umbilical cord serum thyroid stimulating hormone, in Quebec using filter paper thyroxine, and in Belgium using serum thyroid measurement. These and many other programs soon proved that congenital hypothyroidism could indeed be detected biochemically in the newborn period (almost invariably before it was suspected clinically) with great reliability and acceptably low cost $[7,8]$.

Even after 30 years of establishment of congenital hypothyroidism screening programme in most parts of the world, India is still legging behind in formulating a universal policy, data collection about prevalence of congenital hypothyroidism and early detection and treatment. One of the reason is that it is very difficult to call back babies once discharged also an effective social system whereby babies could be reached at home is practically nonexistent.

Thus cord blood remains a very practical alternative for screening purpose and thus in practice in some Asian countries.

\section{Material and Method}

This prospective study was carried out in maternal and neonatal care unit of Department of Pediatrics and Department of Obstetrics and Gynaecology, Batra Hospital and Medical Research Centre, New Delhi from July 2008 to June 2009. The study group comprised of a cohort of neonates born at BHMRC during the study period. The sample size was not predetermined as it was based on cord blood samples obtained during the study period. Ethical approval was obtained from the ethical committee of the institution.

Inclusion criteria: All live newborns delivered in BHMRC during study period.

Exclusion criteria: Newborns whose mother were on any thyroid medication and newborns delivered outside the hospital.

Written consent for collection of cord blood was obtained for parents before delivery. 2-3 $\mathrm{ml}$ of cord blood was collected in a sterile serum separating tubes (BD vaccutainer SST II advance) immediately after birth of babies, drawn from a $15-20 \mathrm{~cm}$ length of umbilical cord incised while severing it at the time of birth of the baby. Thus a mixed umbilical cord blood sample containing blood both from umbilical arteries and veins was obtained.

Records of mother's age, parity, thyroid status, residence, blood pressures, diabetes etc was kept. The medication/anesthesia details received by mother were also noted. At birth baby resuscitated and examined. Weight, sex, time of first cry, APGAR score were noted.

TSH was estimated using electrochemiluminescence immunoassay (ECLIA) on ROCHE Elecsys 2010 system. The method uses monoclonal antibody specifically directed against human TSH. The antibody labeled with ruthenium complex consists of a chimeric construct from human and mouse specific components. As a result interfering affect due to HAMA (Human antimouse antibody) are largely eliminated.

Principle of method: The method is based on sandwich principle. Total assay duration is 18 minute. First incubation includes 50 micro liters of sample a biotinylated monoclonal TSH specific antibody and a monoclonal TSH specific antibody labeled with a ruthenium complex react to form a sandwich complex. In the second incubation, after addition of streptavidin coated microparticles, the complex become bound to the solid phase via interaction of biotin and streptavidin. The reaction mixture in aspirated into the measuring cell where microparticles are magnetically captured onto the surface of electrodes. Unbound substances are then removed with ProCell.. Application of a voltage to the electrode then induces chemiluminescent emission which is measured by a photomultiplier. Results were determined via a calibration curve which is instrumentspecifically generated by 2 point calibration and a master curve provide via the reagent barcode.

Calibration of assay in checked by putting controls. Percent CV for TSH assay was $4 \%$.

Recall Process: Parents of newborns with cord blood TSH $>20 \mathrm{mIU} / \mathrm{L}$ were informed about the test results before discharged from hospital. Retesting was scheduled on their first revisit to pediatrician that usually was at 1 week of age.

Statistical Analysis: The mean, median and standard deviation for TSH values of the cohort were calculated by using windows SPSS (15) software. T-test was applied to see the significance of difference in mean $\mathrm{TSH}$ value of different groups. 


\section{Result}

In our study group $56.14 \%$ newborns were male and $43.86 \%$ were female. Mean cord blood TSH in males was low as compared to female but this difference was statistically significant ( $\mathrm{p}>0.05$ ). Out of 415 newborns $48.19 \%$ were delivered vaginally and $51.8 \%$ by LSCS. Mean cord blood TSH was high in LSCS group (14.41 \pm 19.91$)$ as compared to NVD group (1163 \pm 11.74$)$ but difference was statistically significant $(\mathrm{p}>0.05)$. The mean birth weight of newborns in our study was $2.8 \pm 0.43 \mathrm{~kg}$. 50 th percentile was $3 \mathrm{~kg}$. All newborns were divided in two groups:

i. $\quad$ LBW i.e. $<2.5 \mathrm{~kg}-16.14 \%$ of all newborns were Low Birth Weight.

ii. Normal Birth Weight i.e. $\geq 2.5 \mathrm{Kg}$ - Majority (83.86\%) were Normal Birth Weight.

Mean cord blood TSH was high in low birth weight group (15.97 \pm 21.13$)$ as compared to Normal birth weight newborns $(12.51 \pm 15.48)$ but difference was statistically significant $(\mathrm{p}>0.05)$.

According to gestation by dates, all newborns were classified in two groups -

Preterm ( $<37$ weeks) - 12.53\% newborns were preterm. Term ( $\geq 37$ weeks $)-87.47 \%$ were term newborns

Mean cord blood TSH was high in preterm newborns $(19.34 \pm 26.84)$ as compared to term newborns (12.17 \pm 14.32$)$ but difference was statistically insignificant $(\mathrm{p}>0.05)$. Newborns were divided in 2 groups according to APGARscore given at one minute of age. 9.4\% of newborns had APGAR $<7$ at $1 \mathrm{~min} .96 .6 \%$ of all had APGAR of $>7$. Mean cord blood TSH was high in newborns with APGAR $<7(25.93 \pm 34.52)$ as compared to newborns with APGAR $>7(11.73 \pm 12.74)$ but difference was statistically significant $(\mathrm{p}<0.05)$. Mother of 5.54\% newborns were having PIH; mothers of $94.46 \%$ newborns were normotensive. Mean cord blood TSH was low in newborns with maternal PIH (12.62 \pm 11.42$)$ as compared to newborns with no maternal PIH (12.17 \pm 14.32$)$ but difference was statistically insignificant $(p>0.05)$

Table 1 (A): Sex distribution

\begin{tabular}{|l|l|l|}
\hline Sex & Number & Percentage (\%) \\
\hline Male & 233 & 56.14 \\
\hline Female & 182 & 43.86 \\
\hline Total & $\mathbf{4 1 5}$ & $\mathbf{1 0 0}$ \\
\hline
\end{tabular}

Table 1(B): TSH according to Sex

\begin{tabular}{|l|l|l|}
\hline Sex & Mean Cord blood TSH (mIU/L) & SD \\
\hline Male & 12.80 & 14.94 \\
\hline Female & 13.42 & 18.44 \\
\hline
\end{tabular}

$\mathrm{SD}=$ Standard Deviation

t-test; $\mathrm{p}=0.71$

Table 2 (A): Mode of delivery

\begin{tabular}{|l|l|l|}
\hline Mode of delivery & Number & Percentage (\%) \\
\hline NVD & 200 & 48.19 \\
\hline LSCS & 215 & 51.81 \\
\hline Total & $\mathbf{4 1 5}$ & $\mathbf{1 0 0}$ \\
\hline
\end{tabular}


Table 2 (B): TSH according to MOD

\begin{tabular}{|l|l|l|}
\hline Mode of delivery & Mean Cord blood TSH (mIU/L) & SD \\
\hline NVD & 11.63 & 11.74 \\
\hline LSCS & 14.41 & 19.91 \\
\hline
\end{tabular}

$\mathrm{SD}=$ Standard Deviation

t-test; $\mathrm{p}=0.08$

In our study out of 415 newborns 200 were delivered vaginally and 215 were delivered by LSCS. Mean cord blood TSH in LSCS group was higher than NVD group (14.41 vs. 11.63). No significant difference was found. (Table 2A and 2B). We found no significant difference in mean TSH of low birth weight $(<2500$ gms $)$ and normal birth weight $(>2500$ gms $)$ (Table 3A \& 3B).

Table 3 (A): Birth weight distribution

\begin{tabular}{|l|l|l|}
\hline Birth weight & Number & Percentage (\%) \\
\hline$<2.5$ & 67 & 16.14 \\
\hline$\geq 2.5$ & 348 & 83.86 \\
\hline Total & $\mathbf{4 1 5}$ & $\mathbf{1 0 0}$ \\
\hline
\end{tabular}

Table 3 (B): TSH according to birth weight

\begin{tabular}{|l|l|l|}
\hline Birth weight & Mean Cord blood TSH (mIU/L) & SD \\
\hline$<2.5$ & 15.97 & 21.13 \\
\hline$\geq 2.5$ & 12.51 & 15.48 \\
\hline
\end{tabular}

$\mathrm{SD}=$ Standard Deviation

t-test; $\mathrm{p}=0.20$

Table 4 (A): Gestational age distribution

\begin{tabular}{|l|l|l|}
\hline Gestational age & Number & Percentage (\%) \\
\hline$<37$ & 52 & 12.53 \\
\hline$\geq 37$ & 363 & 87.47 \\
\hline Total & $\mathbf{4 1 5}$ & $\mathbf{1 0 0}$ \\
\hline
\end{tabular}

Table 4 (B): Gestational age distribution

\begin{tabular}{|l|l|l|}
\hline Gestational age & Mean Cord blood TSH (mIU/L) & SD \\
\hline$<37$ & 19.34 & 26.84 \\
\hline$\geq 37$ & 12.17 & 14.32 \\
\hline
\end{tabular}


$\mathrm{SD}=$ Standard Deviation

t-test; $\mathrm{p}=0.06$

We found a significantly high mean cord blood TSH in newborns with APGAR $<7$ as compared to newborns with APGAR $>7$ (Table 5A \& 5B). .

Our study cohort contained $12.53 \%$ as preterm babies who delivered at gestation $<37$ weeks and $87.47 \%$ of term newborns delivered at $\geq 37$ weeks. We found no significant difference in mean cord blood TSH in both groups (Table 4A \& 4B).

Table 5 (A): APGAR score distribution

\begin{tabular}{|l|l|l|}
\hline Apgar at 1 min. & Number & Percentage (\%) \\
\hline$<7$ & 39 & 9.40 \\
\hline$\geq 7$ & 376 & 90.60 \\
\hline Total & $\mathbf{4 1 5}$ & $\mathbf{1 0 0}$ \\
\hline
\end{tabular}

Table 5 (B): TSH according to APGAR

\begin{tabular}{|l|l|l|}
\hline Apgar at 1 min & Mean Cord blood TSH (mIU/L) & SD \\
\hline$<7$ & 25.93 & 34.52 \\
\hline$\geq 7$ & 11.73 & 12.74 \\
\hline
\end{tabular}

$\mathrm{SD}=$ Standard Deviation

t-test; $\mathrm{p}=0.01$

We found no significant difference in cord blood TSH of newborn with maternal PIH and with normotensive mother (Table 6A \& 6B).

\section{Table 6 (A): PIH distribution}

\begin{tabular}{|l|l|l|}
\hline PIH distribution & Number & Percentage (\%) \\
\hline Present & 23 & 5.54 \\
\hline Absent & 392 & 94.46 \\
\hline Total & $\mathbf{4 1 5}$ & $\mathbf{1 0 0}$ \\
\hline
\end{tabular}

$\mathrm{PIH}=$ Pregnancy Induced Hypertension

Table 6 (B): TSH according to PIH

\begin{tabular}{|l|l|l|}
\hline PIH distribution & Mean Cord blood TSH (mIU/L) & SD \\
\hline Present & 25.93 & 34.52 \\
\hline Absent & 11.73 & 12.74 \\
\hline
\end{tabular}

$\mathrm{SD}=$ Standard Deviation

t-test; $\mathrm{p}=0.85$

In our study of 415 newborns mean \pm SD cord blood TSH was $8.4 \mathrm{mIU} / \mathrm{L}$ and mode was $7.3 \mathrm{mIU} / \mathrm{L}$ (Table 7 \& 8). . 
Table 7: TSH distribution

\begin{tabular}{|l|l|l|}
\hline TSH (mIU/L) & Number & Percentage (\%) \\
\hline$<20$ & 377 & 89.40 \\
\hline$>20$ & 44 & 10.60 \\
\hline Total & $\mathbf{4 1 5}$ & $\mathbf{1 0 0}$ \\
\hline
\end{tabular}

Table 8: Incidence of Congenital hypothyroidism in our study

\begin{tabular}{|l|l|}
\hline Total Newborns screened & 415 \\
\hline Mean Cord Blood TSH (mIU/L) & 13.1 \\
\hline Standard deviation & 16.55 \\
\hline Total newborns Recalled & 44 \\
\hline Recall Rate (\%) & 10.6 \\
\hline Repeat Thyroid Function done & 44 \\
\hline Recall response rate (\%) & 100 \\
\hline Congenital Hypothyroidism confirmed on repeat testing & 01 \\
\hline
\end{tabular}

\section{Discussion}

415 newborns were delivered in our institution during our study period were included. In our study male:female ratio was $1.28: 1$. We found no significant difference in mean cord blood TSH of male and female. (Table 1A and 1B). Feleke et al studied [9] 4206 newborns serum TSH and also found no differences in mean TSH of male and female. RC Franklin et al [10] in a study of 229 healthy term neonate also found no significant difference in mean cord blood TSH in newborns delivered by different mode of delivery. Mekonnen [11] compared 128 low birth weight infants with 790 normal birth weight babies and found no significant difference in both groups comparable to our study. ). Rashmi et al [12] shares the same observation .Infants with birth asphyxia (Apgar score $<4$ at $5 \mathrm{~min}$ ) had significantly higher Cord Blood TSH levels (mean $31 \mathrm{microU} / \mathrm{ml}, \mathrm{n}=18$ ) as compared to those without (mean $10.4 \mathrm{microU} / \mathrm{ml})(\mathrm{p}<0.01)$. Mean cord blood $\mathrm{TSH}$ and standard deviation values in our study are high because of inclusion of asphyxiated babies. We have also not considered newborns with perinatal fetal distress and newborn delivered by vacuum or forceps separately. We have used ECLIA method for TSH assay which is more sensitive than IRMA. Most of previous studies used IRMA or other method but not ECLIA. Ward et al [13] in a study comparing 90 newborns with maternal PIH with 140 newborns with normotensive mother as we found in presnt study. ). Khadilkar et al [14] obtained mean TSH 12.3 \pm 4.9 . Rashmi et al [12] obtained mean cord blood TSH as $10.6 \mathrm{mIU} / \mathrm{L}$ in 1590 newborns. In our study of mean \pm SD cord blood TSH was $8.4 \mathrm{mIU} / \mathrm{L}$ and mode was $7.3 \mathrm{mIU} / \mathrm{L}$ (Table 7 ). In our study 44 out of 415 $(10.6 \%)$ newborns were found to have cord blood TSH value more than cut off value of $20 \mathrm{mIU} / \mathrm{L}$. According to our study these newborns were recalled for retesting for thyroid function. Hardy $\mathrm{JD}[15]$ in a study using cord blood TSH found recall rate of 4.5\% [Table 7 and 8]. Incidence of congenital hypothyroidism in our study was 1 in 415 .

This is much higher as compared to worldwide figure of 1 in 4000 [16] but other Indian data too have quoted higher incidence. Desai MP, Lolaco MP et al in their study using cord blood TSH found an incidence of 1 in 2481. [17] Arun Kumar Manglik et al in 1200 cord blood samples of term babies found an incidence of congenital hypothyroidism 1 in 600 [18]. 


\section{Conclusion}

\section{"Prevention is better than cure"}

Congenital hypothyroidism $(\mathrm{CH})$ is a major preventable cause of mental retardation. It has worldwide incidence of 1 in 4000 births and some studies indicating a higher incidence in India. Neonatal screening programmes for detection of Congeniatl Hypothyroidism in neonatal period are widespread in developed countries for the last three decades and are fast gaining momentum in the developing world as well. In our country there is no screening programme for Congenital Hypothyroidism. Our hospital has recently started the screening programme for Congenital Hypothyroidism. We have carried out this study to find out the normative and mean values of cord blood TSH and to evaluate the effect of various perinatal factors on umbilical cord blood TSH. We conclude that cord blood TSH is very effective method for Congenital Hypothyroidism screening in India. It is not affected by various perinatal factors except perinatal asphyxia. Cord blood TSH gives us opportunity to collect sample of maximum newborns for screening and rapid testing using ECLIA helps in communicating report to parents before they get discharged. With early results using Cord blood TSH and ECLIA, we can counsel them about the severity of disease and treatment option thereby increasing response for recalling. We feel Congenital Hypothyroidism screening should be included in National Health Policy.

\section{Funding: Nill}

Conflict of Interest: None

Permission of IRB: Yes

\section{References}

1. Osler W. Sporadic cretinism in America. Transactions of the congress of American Physicians and Surgeons. 1897;4:169-206.

2. Pickering DE, Fisher DA: Therapeutic concept relating to hypothyroidism in childhood. J Chron Dis. J Chronic Dis. 1958 Mar;7(3):242-63

3. Eayrs JT: Influence of the thyroid on the central nervous system, British Medical Bulletin. 1960 May;16:122-7.

4. P. Reed Larsen, Sidney H. Ingbar. The Thyroid Gland in: Wilson Foster Editor. Williams Text book of Endocrinology, 7th edition. Saunders: International edition: 447-448.
5. Smith DW, Blizzard RM, Wilkins L. The mental prognosis in hypothyroidism of infancy and childhood. A review of 128 cases. Pediatrics 1957 Jun;19(6):101122.

6. Klein AH, Meltzer S, Kenny FM. Improved prognosis in congenital hypothyroidism treated before age three months. J Pediatr. 1972 Nov;81(5):912-5.

7. Fisher DA, Dussault JH, Foley TP Jr. et al. Screening for congenital hypothyroidism: results of screening one million North American infants. J Pediatr.1979 May;94(5):700-5.

8. Newborn Committee of the European Thyroid Association. Neonatal screening for congenital hypothyroidism in Europe. Acta Endocrinol. suppl (copenh). 1979;223:3-29.

9. Feleke Y, Enquosellasie F, Deneke F, Abdulkadir J, Hawariat GW, Tilahun M, et al. Neonatal congenital hypothyroidism screening in Addis Ababa, Ethiopia. East Afrc Med J.2000;77(7):377-381.

10. Franklin RC, Carpenter LM, O'grady CM. Neonatal thyroid function: influence of perinatal factors. Arch Dis Child. 1985 feb;60(2):141-4.

11. Yalemtsehay Mekonnen, Gizachew W Hawariat, Bekele Chamiso, Friedhelm Raue. Thyroid stimulating hormone values from cord blood in neonates. Ethiop. J. Health Dev. 2003;17(2):125-130.

12. Rashmi, Seth A, Sekhri T, Agarwal A. Effect of perinatal factors on cord blood thyroid stimulating hormone levels. J Pediatr Endocrinol Metab. 2007 Jan;20(1):59-64.

13. Ward LS, Kunni IS, DE Barros Maciel RM. Thyroid stimulating hormone levels in cord blood are not influenced by non thyroidal mothers diseases. Sao Paulo Med J. 2000 Sep 7;118(5):114-7.

14. Khadilkar V, Khadilkar A, Cowasji H. Neonatal thyroid screening program using filter paper method. Cape News 2002;6:1.

15. Hardy JD, Azyed R, Doss I, Dhatt GS. Cord blood thyroxine and thyroid stimulating hormone screening for congenital hypothyroidism: how useful are they? J Pediatr Endocrinol Metab. 2008 Mar;21(3):245-9. 
16. Lafranchi S, Hypothyroidism IN: Behrman RE, Kleigman RM, Jenson HB, editors. Nelson Textbook of Pediatrics, 18th ed. Philadelphia: Saunders. 2008:23162324.

17. Desai MP, Colaco MP, Ajgaokar AR, Mahadik CV, Rege C, Shiordkar VV et al. Neonatal screening for congenital hypothyroidism in a developing country: problems and strategies. Indian J Pediatr, 1987 julaug;54(4):571-81.

18. Manglik Arun Kumar, Chatterjee Nandita and Ghosh Gautam. Umbilical Cord Blood TSH Levels in Term Neonates: A Screening Tool for Congenital Hypothyroidism Indian Pediatrics. 2005;42:1029-1032.

\section{How to cite this article?}

Garg P. To study umbilical cord blood TSH values in newborn in BHMRC over a period of 1 year: Int J Pediatr Res 2016;3(2):105-112.doi:10.17511/ijpr.2016.i02.07. 